\title{
VARIAÇÕES GENÉTICAS EM POPULAÇÃOES DE Eucalyptus spp. DETECTADAS POR MEIO DE MARCADORES MOLECULARES ${ }^{1}$
}

\author{
Ronaldo Pereira Caixeta ${ }^{2}$, Dulcinéia de Carvalho ${ }^{3}$, Sebastião Carlos da Silva Rosado e Paulo Fernando Trugilho ${ }^{3}$
}

\begin{abstract}
RESUMO - A tecnologia de marcadores moleculares, aliada às técnicas clássicas do melhoramento, pode contribuir significativamente para o conhecimento básico da cultura e do caráter estudado e para a geração e o desenvolvimento de produtos melhorados. O objetivo deste trabalho foi utilizar marcadores RAPD para detectar e maximizar a variabilidade genética em genótipos Eucalyptus, identificando cruzamentos favoráveis para um programa de melhoramento florestal, visando o uso múltiplo. Foram analisados 44 genótipos de híbridos naturais do gênero Eucalyptus, plantados na região noroeste de Minas Gerais. Os marcadores moleculares RAPD apresentaram poder de discriminação eficiente entre os 44 genótipos avaliados, constatando-se uma distância genética média entre os genótipos de Eucalyptus de 54\% e divergência genética variando de 24 a $73 \%$. Este fato indica que entre os indivíduos analisados existe uma ampla base genética, o que possibilita a manipulação desse material em programas de melhoramento. A distância genética entre os genótipos 5 e 9; 9 e 10; 9 e 19; 9 e 25; 9 e 33; 9 e 35; 9 e 36; 9 e 44; 10 e 33; 12 e 19; 12 e 33; e 12 e 39 apresentou-se maior ou igual a 70\%. A análise de agrupamento estabelecida, utilizando UPGMA e o critério de corte de $80 \%$ da distância genética total, permitiu a formação de nove grupos distintos. Esses grupos apresentaram divergência genética média superior a $60 \%$. A maior média de distância ocorreu entre o grupo I e os demais, com 67\%. A avaliação por marcadores moleculares RAPD forneceu uma identificação direta da variação genética dos genótipos e, neste sentido, novos cruzamentos para produção de híbridos específicos poderão ser gerados, aumentando, assim, a divergência genética e a produtividade de derivados de madeira de qualidade superior para usos múltiplos em programas de melhoramento florestal.
\end{abstract}

Palavras-chave: Marcador molecular, Eucalyptus e variações genéticas.

\section{GENETIC VARIATIONS IN Eucalyptus spp. GENOTYPES DETECTED BY MEANS OF MOLECULAR MARKERS}

\begin{abstract}
Molecular marker technology combined with the classic breeding techniques can contribute significantly to a basic understanding of the crop and character investigated and help generate and develop improved products. The objective of this work is to utilize RAPD markers to detect and maximize the genetic variability in eucalyptus genotypes, identifying crossings favorable to a forest breeding program, aiming at multiple use. A total of 44 natural hybrid genotypes of the Eucalyptus genus, planted in northwestern Minas Gerais was analyzed. The RAPD molecular markers presented efficient discriminating power among the 44 evaluated genotypes, determining an average genetic distance among them of 54\% and genetic divergence ranging from 24 to $73 \%$. This shows that there is a wide genetic basis among the individuals analyzed, allowing a manipulation of this material in breeding programs. The genetic distance among the genotypes 5 and 9; 9 and 10; 9 and 19; 9 and 25; 9 and 33; 9 and 35; 9 and 36; 9 and 44;10 and 33; 12 and 19;12 and 33; 12 and 39 proved to be either greater or equal to $70 \%$. Grouping analysis established by the UPGMA method, and the cut of $80 \%$ of the total genetic distance as a criterion allowed the formation of nine distinct groups. These groups presented an average genetic divergence superior to $60 \%$. The highest mean of distance occurred between group I and the remaining groups, with $67 \%$. The evaluation by RAPD molecular markers provided an indirect identification of the genetic variation of the genotypes and, in this sense, new crosses for the production of specific hybrids can be generated, increasing the genetic divergence and yield of wood products of superior quality for multiple uses in forest breeding programs.
\end{abstract}

Key words: $\quad$ Molecular markers, Eucalyptus and genetic variations.

1 Recebido para publicação em 25.10.2001.

Aceito para publicação em 12.5.2003.

2 Mestrado de Ciência e Tecnologia da Madeira, Universidade Federal de Lavras - UFLA, 37200-000 Lavras-MG; ${ }^{3}$ Professores do Departamento de Ciências Florestais da UFLA. 


\section{INTRODUÇÃO}

As florestas plantadas com o gênero Eucalpytus merecem destaque no setor florestal brasileiro, pois, nos últimos anos, a sua silvicultura alcançou alto nível de desenvolvimento tecnológico. Neste avanço destaca-se o melhoramento genético, que propiciou ganhos de grande magnitude, principalmente na produtividade volumétrica. No entanto, alguns questionamentos têm surgido a respeito das populações introduzidas no Brasil, quanto à sua origem e ao conhecimento em termos de sua divergência genética, pois estes materiais foram introduzidos a partir de populações de plantios naturais da Austrália e da África do Sul, e aqui pode ou não ter ocorrido um processo de redução desta diversidade em razão de cruzamento entre indivíduos aparentados ou do pequeno número efetivo de indivíduos utilizados nos locais de coleta de sementes.

Portanto, para implantação de programas de melhoramento genético a partir dessas populações de Eucalyptus spp. torna-se imprescindível conhecer a divergência genética, com os objetivos de identificar clones ou genótipos para instalação de pomares de sementes clonais; maximizar a distância genética pela recombinação de genes ou complexos gênicos em novas combinações favoráveis; e fazer uma seleção indireta e precoce para características da madeira, para avaliar as propriedades físicas, mecânicas, químicas e anatômicas e tornar a seleção precoce mais eficiente, aumentando o ganho genético por unidade de tempo.

Uma forma muito eficaz de detectar a variabilidade genética é por meio do uso de marcadores moleculares, sendo o RAPD (Random Amplified Polymorphic DNA) um dos mais utilizados. Esta técnica baseia-se na amplificação do fragmento de DNA, que é flanqueado por um par de oligonucleotídeos que hibridizam em direções opostas à seqüência-alvo, por meio de ciclos de desnaturação, anelamento do primer e extensão pela enzima Taq polimerase (Ferreira \& Grattapaglia, 1998).

A avaliação utilizando marcadores moleculares RAPD pode fornecer uma identificação direta da variabilidade genética e, neste sentido, indicar genitores para produção de híbridos específicos, visando assim o aumento da divergência genética nas próximas gerações a serem utilizadas em futuros programas de melhoramento florestal.

Os objetivos deste trabalho foram avaliar a variabilidade genética em populações de Eucalpytus spp. e identificar genitores divergentes para cruzamentos preferenciais na geração de híbridos em programas de melhoramento genético.

\section{MATERIAL E MÉTODOS}

\subsection{Material Biológico}

Foram analisados 44 genótipos de híbridos naturais do gênero Eucalyptus, provenientes da fazenda Bom Sucesso, propriedade da Companhia Mineira de Metais (CMM-AGRO), pertencente ao grupo Votorantim. A fazenda Bom Sucesso está localizada no município de Vazante-MG, à latitude de $17^{\circ} 36^{\prime} 09^{\prime}$ ' S e longitude de $46^{\circ} 42^{\prime} 02^{\prime}$ " oeste de Greenwich, e altitude de $550 \mathrm{~m}$. O clima da área é do tipo Aw, tropical úmido de savana, com inverno seco e verão chuvoso, segundo a classificação climática de Köppen. A temperatura média anual é de $24^{\circ} \mathrm{C}$ e a precipitação média anual de $1.450 \mathrm{~mm}$.

Para análise do DNA, utilizaram-se folhas coletadas nas mudas feitas por estaquia, oriundas de brotações das árvores remanescentes no campo após o corte. As folhas recém-colhidas foram identificadas e mantidas no gelo para o transporte até o laboratório e, em seguida, procedeu-se às extrações do DNA.

\subsection{Extração do DNA}

As extrações de DNA foram feitas de acordo com o procedimento descrito por Nienhuis et al. (1995), por maceração do material vegetal com nitrogênio líquido, utilizando-se $1,0 \mathrm{~g}$ de folhas, sendo adicionados $10 \mathrm{ml}$ de tampão de extração CTAB e $20 \mu 1 \mathrm{de}$ $\beta$-mercaptoetanol, para retardar a oxidação de metabólitos secundários, permanecendo em banho-maria a $65^{\circ} \mathrm{C}$ por 60 minutos.

Após esse período, foram adicionados $5 \mathrm{ml}$ de mistura de clorofórmio-álcool isoamílico (24:1) e os tubos foram agitados lentamente 50 vezes, para obtenção de uma emulsão, e, posteriormente centrifugados a 7.000 rpm, em centrífuga Hitachi, por 30 minutos. O sobrenadante foi pipetado, vertido em $15 \mathrm{ml}$ de propanol e condicionado no freezer $\left(-20^{\circ} \mathrm{C}\right)$ por uma noite, para precipitação dos ácidos nucléicos.

Após a precipitação, foram adicionados $100 \mu \mathrm{lde}$ $\mathrm{EtOH}$, deixando-se 10 minutos em temperatura ambiente, e procedeu-se a uma nova centrifugação por 10 minutos, a $4.000 \mathrm{rpm}$, sendo assim possível retirar o sobrenadante 
e secar o "pellet" em capela de fluxo laminar. Após a secagem, adicionou-se TE para solubilização do DNA.

A quantificação da concentração de DNA das amostras foi determinada por um fluorímetro (DYNA Quant 200). Para cada amostra foram utilizados $2 \mu \mathrm{lde}$ DNA e $2 \mathrm{ml}$ de tampão TNE 10x (Tris base $100 \mathrm{mM}$; $\mathrm{Na}_{2}$ EDTA, $\mathrm{Na}_{2}, 2 \mathrm{H}_{2} \mathrm{O} 10 \mathrm{mM}$ e $\mathrm{NaCl} 2 \mathrm{M}$, sendo o $\mathrm{pH}=7,4)$.

\subsection{Análise RAPD}

As reações RAPD foram baseadas no método descrito por Williams et al. (1990), usando oligonucleotídeos de dez bases de seqüência arbitrária com algumas modificações, tendo as reações sido otimizadas para obtenção de produtos de amplificação de melhor qualidade. Foram empregados 23 oligonucleotídeos da marca (Operon Technologies Inc., Alameda, Califórnia), para geração de polimorfismo.

Os produtos da amplificação foram separados em géis de 1,0\% de agarose e corados com brometo de etídio e, então, visualizados em transiluminador de luz ultravioleta. Os géis foram fotografados, utilizando-se filme Polaroid 667.

\subsection{Análise dos Dados Moleculares}

$\mathrm{Na}$ avaliação dos géis, cada banda foi tratada como um caráter único, sendo a sua presença em um indivíduo designada por 1 e a ausência em outro indivíduo, por 0 (zero). De posse desses dados, foi construída uma matriz de 0 e 1 . A presença de uma banda entre os dois genótipos comparados foi considerada como similaridade e a presença em um dos genótipos e ausência no outro, considerada como diferente.

A distância genética foi calculada aos pares, utilizando-se o índice de similaridade de Jaccard (Jaccard, 1908), segundo a expressão:

$$
d i i^{\prime}=\left(1-S i i^{\prime}\right) \times 100
$$

em que $d i i$ ' = é a distância genética entre os genótipos $i$ e $i^{\prime}$; e $S i i "=$ é o índice de similaridade de Jaccard.

sendo:

$$
S i i^{\prime} \frac{a}{a+b+c}
$$

em que $a=$ número de bandas presentes nos dois genótipos analisados; $b=$ número de bandas presentes apenas no genótipo $i$; e $c=$ número de bandas presentes apenas no genótipo $i$ '.

Os erros associados a cada distância foram estimados segundo Skroch et al. (1992), pela seguinte expressão:

$$
V=\frac{n d(1-d)}{(n-1)}
$$

em que $\mathrm{V}=$ variância da distância genética entre cada par de populações; $\mathrm{d}=$ distância genética entre cada para de populações; e $\mathrm{n}=$ número total de bandas utilizadas na estimativa da distância genética. Erro-padrão estimado $=(\mathrm{V} / \mathrm{n})^{1 / 2}$

A representação simplificada das distâncias genéticas foi efetuada por meio de dendrogramas obtidos pelo método hierárquico aglomerativo da média aritmética entre pares não-ponderados (UPGMA).

\section{RESULTADOS E DISCUSSÃO}

\subsection{Reação de RAPD}

Os oligonucleotídeos utlizados geraram pelo menos uma banda polimórfica entre os indivíduos analisados (Quadro 1). Estes oligonucleotídeos de síntese de cadeia curta (dez nucleotídeos) podem encontrar-se aleatoriamente em regiões de homologia no DNA do genótipo analisado, fornecendo, assim, um ponto de início de síntese para o DNA polimerase.

Os 23 oligonucleotídeos geraram 132 produtos de amplificação, com uma média de 5,74 bandas. Deste total, 101 bandas foram polimórficas, igual a 76,52\%, sendo 4,39 bandas, e 31 foram monomórficas, igual a 23,48\%, sendo 1,35 banda. $\mathrm{O}$ número de bandas amplificadas variou de acordo com o oligonucleotídeo, tendo alguns propiciado a amplificação de três bandas e outros de até dez bandas. Observa-se, no Quadro 1, que os resultados indicam um alto grau de polimorfismo entre os genótipos de Eucapyptus, fato que pode ser observado pelo padrão de fragmentos amplificados com a utilização do primer OPJ-17, conforme demonstração apresentada na Figura 1. Segundo Esbrisse (1998), o alto grau de polimorfismo pode ser um reflexo da alogamia, aliado ao fato de as árvores-matrizes analisadas serem provenientes da primeira geração de seleção.

R. Árvore, Viçosa-MG, v.27, n.3, p.357-363, 2003 
Quadro 1 - Oligonucleotídeos utilizados e respectiva seqüência de bases, número de banda polimórficas e monomórficas para os 44 genótipos estudados

Table 1 - Oligonucleotides used and respective sequence of bases, number of polymorphic and monomorphic bands for the 44 genotypes studied

\begin{tabular}{|c|c|c|c|}
\hline $\begin{array}{c}\text { Oligonu- } \\
\text { cleotídeo }\end{array}$ & $\begin{array}{c}\text { Seqüência } \\
\left(5^{\prime}-3^{\prime}\right)\end{array}$ & $\begin{array}{c}\text { № Bandas } \\
\text { Polimórficas }\end{array}$ & $\begin{array}{c}\text { № Bandas } \\
\text { Monomórficas }\end{array}$ \\
\hline OPA-18 & AGGTGACCGT & 4 & 2 \\
OPB-01 & GTTTCGCTCC & 6 & 3 \\
OPB-19 & ACCCCGAAG & 4 & 1 \\
OPB-02 & TGATCCCTGG & 2 & 1 \\
OPD-08 & GTGTGCCCCA & 3 & 1 \\
OPJ-09 & TGAGCCTCAC & 4 & 1 \\
OPJ-12 & GTCCCGTGGT & 5 & 0 \\
OPJ-13 & CCACACTACC & 7 & 3 \\
OPJ-16 & CTGCTTAGGG & 7 & 3 \\
OPJ-17 & ACGCCAGTTC & 5 & 1 \\
OPJ-18 & TGGTCGCAGA & 5 & 4 \\
OPJ-19 & GGACACCACT & 2 & 1 \\
OPJ-20 & AAGCGGCCTC & 2 & 2 \\
OPM-14 & AGGGTCGTTC & 5 & 1 \\
OPM-17 & TCAGTCCGGG & 5 & 0 \\
OPN-01 & CTCACGTTGG & 3 & 0 \\
OPN-02 & ACCAGGGGCA & 4 & 1 \\
OPN-03 & GGTACTCCCC & 6 & 0 \\
OPN-05 & ACTGAACGCC & 7 & 1 \\
OPN-07 & CAGCCCAGAG & 5 & 2 \\
OPN-09 & TGCCGGCTTG & 3 & 1 \\
OPN-15 & CAGCGACTGT & 2 & 1 \\
OPX-07 & GAGCGAGGCT & 5 & 1 \\
\hline Total & & 101 & 31 \\
\hline
\end{tabular}

As 101 bandas polimórficas utilizadas são consideradas suficientes, pois segundo Nienhuis et al. (1995), a partir de 100 bandas, praticamente ocorre uma estabilização do coeficiente de variação das distâncias genéticas entre os genótipos.

\subsection{Avaliação de Divergência Genética}

O cálculo da distância genética foi feito com base nas 101 bandas RAPD polimórficas obtidas. Foi construída uma matriz de distâncias genéticas, utilizando o programa Genes (1998), a partir do complemento do coeficiente de similaridade de Jaccard (Jaccard, 1908), que é dado pela razão entre o número de bandas comuns a dois genótipos e o número total de banda, comuns e não comuns entre eles.
A distância genética média entre os genótipos foi de $54 \%$, o erro-padrão médio foi de $4,93 \%$ e a amplitude das distâncias variou de 24 a $73 \%$. Estes resultados demonstraram que existem possibilidades de ganho genético por meio de cruzamentos entre os genótipos analisados, pois a distância entre eles pode ser considerada alta. Já a elevada amplitude das distâncias possibilita a manipulação desse material nos programas de melhoramento, inclusive permitindo selecionar genótipos que ampliam a base genética do material. Por exemplo, os genótipos 5 e 9; 9 e 10; 9 e 19; 9 e 25; 9 e 33; 9 e 35; 9 e 36; 9 e 44; 10 e 33, 12 e 19; 12 e 33; e 12 e 39 apresentaram distâncias entre si iguais ou superiores a $70 \%$, mostrando, assim, ser extremamente divergentes.

Os genótipos que apresentaram as menores divergências foram 2 e $8 ; 22$ e $23 ; 31$ e 34 ; e 34 e 44 , com distâncias genéticas de, respectivamente, $30,24,28$ e $27 \%$.

Com o propósito de avaliar o poder de discriminação dos marcadores RAPD, com base nas distâncias genéticas obtidas, procedeu-se a uma análise de agrupamento pelo método UPGMA (Figura 2), formando nove grupos distintos. O Quadro 2 apresenta os grupos formados, tendo sido utilizado como critério um corte a $80 \%$ da distância genética total, conforme o dendrograma mostrado pela Figura 2.

No Quadro 2 constata-se que os grupos formados apresentam, na sua composição, número distinto de indivíduos, mostrando, assim, que o poder de discriminação dos genótipos é bastante diferenciado.

Quadro 2 - Agrupamento de genótipos de Eucalyptus formado por dendrograma obtido pelo método UPGMA, estabelecendo uma linha de corte a $80 \%$ de dissimilaridade

Table 2 - Eucalyptus genotype grouping by dendrogram obtained by the UPGMA method, establishing a cutting line of $8 \%$ dissimilarity

\begin{tabular}{|l|l|}
\hline Grupo & \multicolumn{1}{|c|}{ Genótipos } \\
\hline I & 9 \\
II & 111314 \\
III & 12 \\
IV & 10 \\
V & 1819 \\
VI & 242526282930313233343536373839404142 \\
VII & 4344 \\
VIII & 151720212223 \\
IX & 122457816 \\
\hline
\end{tabular}



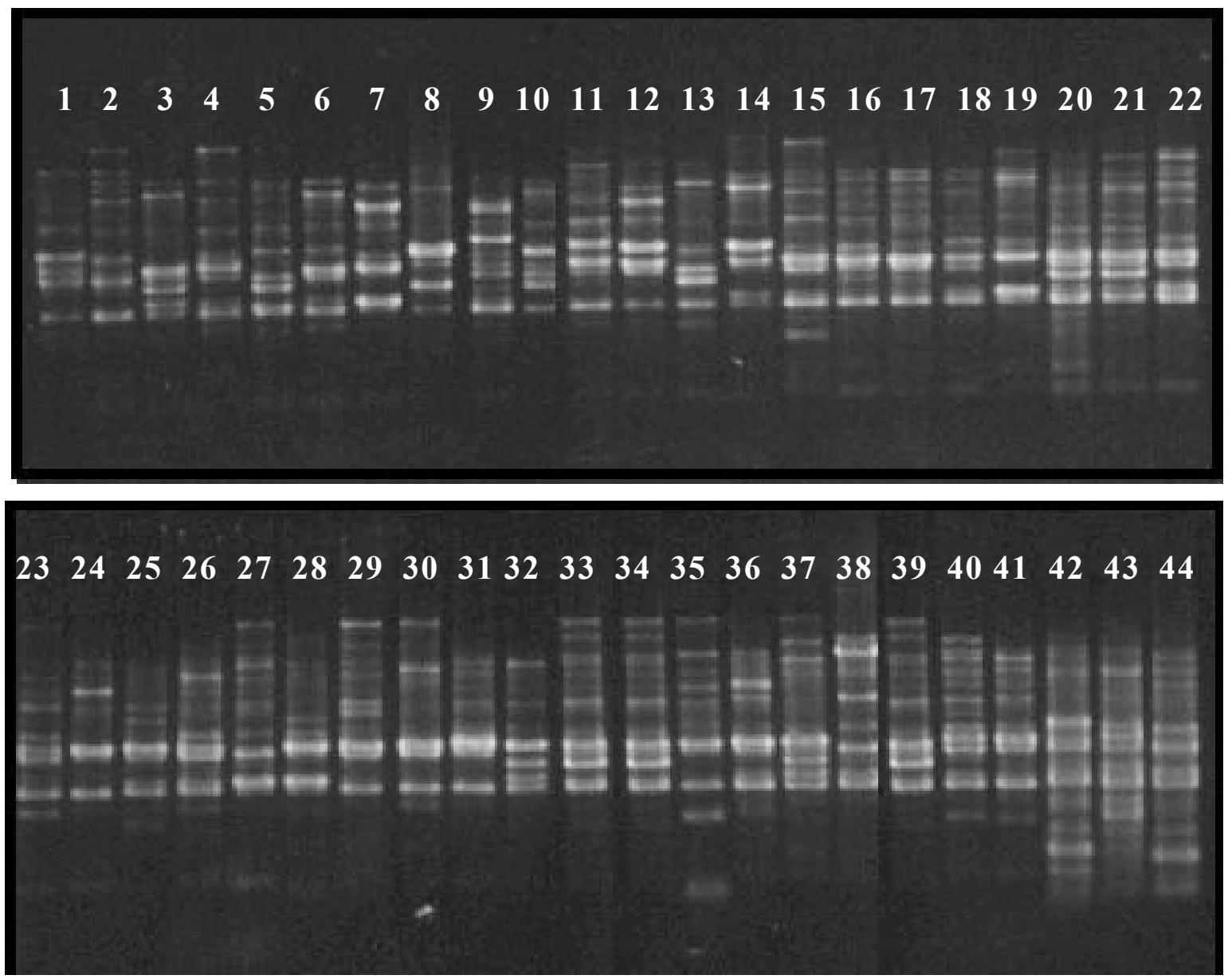

Figura 1 - Eletroforese em gel de agarose mostrando padrões de bandeamento de fragmentos de DNA amplificados por PCR com uso do oligonucleotídeo OPJ-17. As canaletas de 1 a 44 representam os genótipos avaliados.

Figure 1 -Agar gel electrophoresis showing patterns of DNA fragment banding amplified by PCR, using OPJ-17 oligonucleotides. The bands from 1 to 44 represent the genotypes evaluated.

Utilizando a composição do agrupamento obtido pelo dendrogama construído pelo método UPGMA, foi elaborada uma matriz de divergência genética entre e dentro dos nove grupos obtidos, e também foram identificados quais seriam os genótipos mais promissores para maximizar as distâncias entre os grupos (Quadro 3).

Os grupos que apresentam divergência genética superior a $60 \%$ de distância são: grupo I e os demais; grupo III com o V, VI, VII, VII e IX; e os grupos V e VIII. A maior distância genética média ocorreu entre os grupos I e IV. A maior média intergrupo foi obtida entre o grupo I e os demais, com $67 \%$ de distância. O genótipo 9 provavelmente poderá ser utilizado em programa de produção de híbridos em cruzamentos específicos com genótipos 05, 06, 10,12,14, 15, 19 e 33. Dentre estes, devem ser priorizados aqueles com propriedades da madeira favorável a usos específicos.

Os grupos IV, V, VI, VII e VIII apresentam as menores distâncias genéticas em relação aos demais.

As distâncias intragrupos foram menores que as intergrupos, apresentadas no Quadro 3 na diagonal principal, indicando, desta forma, que a variabilidade genética poderá ser aumentada quando proceder a cruzamentos entre grupos, e não dentro do grupo. Esses híbridos poderão ser formados pela utilização proposta de cruzamentos de genótipos na diagonal acima do Quadro 3, que maximiza a distância genética entre grupos para os mais divergentes.

R. Árvore, Viçosa-MG, v.27, n.3, p.357-363, 2003 


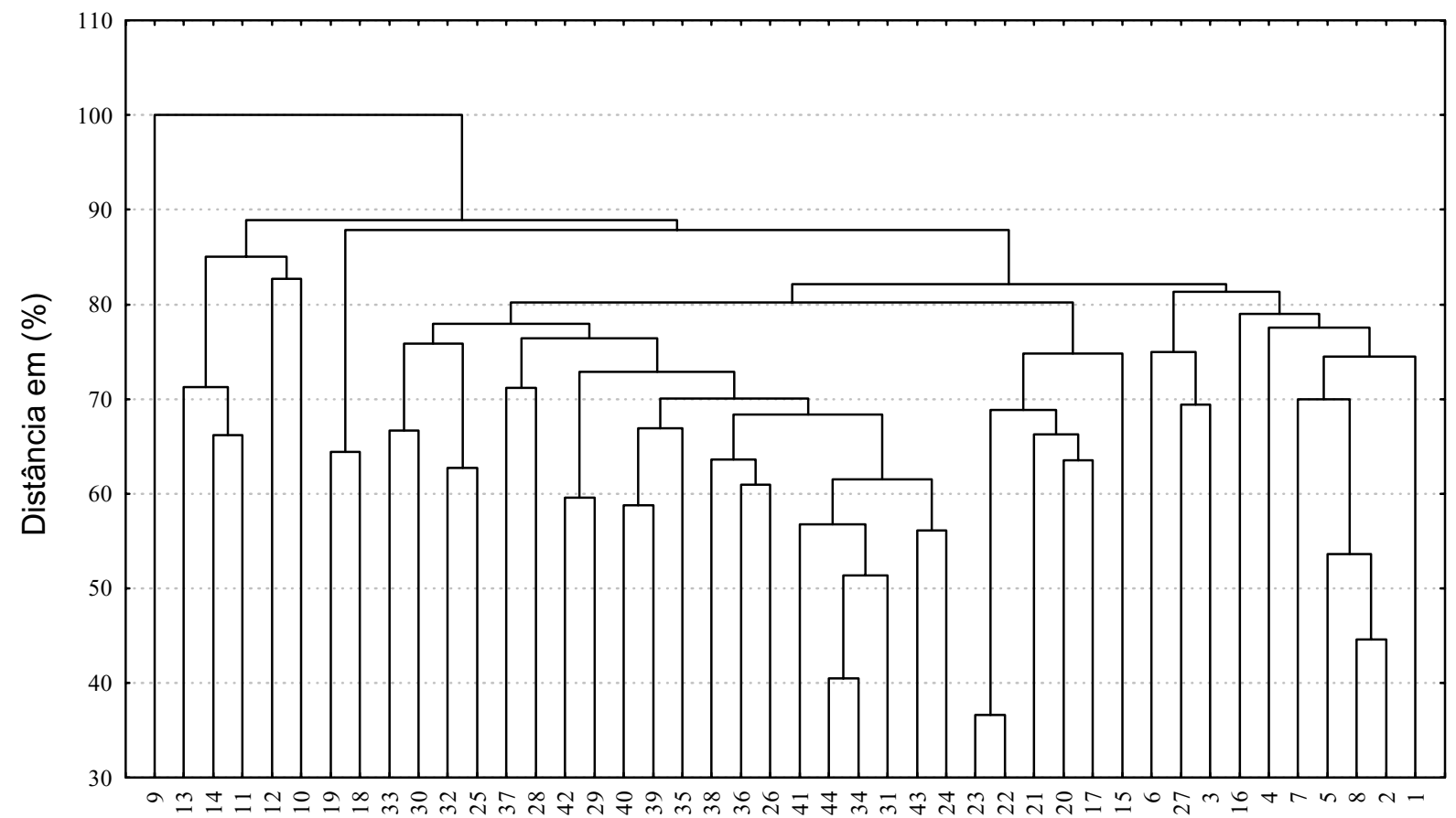

Figura 3 - Dendrograma obtido pelo método de agrupamento UPGMA, com base na dissimilaridade genética entre os 44 genótipo de Eucalyptus pesquisados.

Figure 3 -Dendrogram obtained by the grouping method UPGMA, based on genetic dissimilarity among the 44 Eucalyptus genotypes studied.

Quadro 3 - Matriz de distância genética (\%) entre os nove grupos definidos pelo dendrograma (abaixo da diagonal) e dentro do grupo (na diagonal), e maximização das distâncias entre os grupos através dos genótipos

Table 3 - Genetic distance matrix (\%) among the nine groups defined by the dendrogram (below the diagonal) and within the group (in the diagonal) and maximization of the distances among the groups through the genotypes

\begin{tabular}{|l|c|c|c|c|c|c|c|c|c|}
\hline & G I & G II & G III & G IV & G V & G VI & G VII & G VIII & G IX \\
\hline G I & - & $9 \times 14$ & $9 \times 12$ & $9 \times 10$ & $9 \times 19$ & $9 \times 33$ & $9 \times 15$ & $9 \times 6$ & $9 \times 5$ \\
\hline G II & 65 & 46 & $14 \times 12$ & $13 \times 10$ & $\begin{array}{c}14 \times 18 \\
11 \times 18\end{array}$ & $\begin{array}{c}13 \times 38 \\
14 \times 30\end{array}$ & $13 \times 23$ & $\begin{array}{c}13 \times 6 \\
13 \times 6\end{array}$ & $13 \times 7$ \\
\hline G III & 68 & 57 & - & $12 \times 10$ & $12 \times 19$ & $\begin{array}{c}14 \times 33 \\
12 \times 39\end{array}$ & $12 \times 21$ & $\begin{array}{c}12 \times 27 \\
12 \times 3\end{array}$ & $12 \times 7$ \\
\hline G IV & 72 & 55 & 55 & - & $10 \times 18$ & $10 \times 33$ & $10 \times 21$ & $10 \times 27$ & $10 \times 7$ \\
\hline G V & 69 & 56 & 67 & 58 & 43 & $18 \times 33$ & $18 \times 15$ & $18 \times 27$ & $19 \times 3$ \\
\hline G VI & 67 & 57 & 62 & 62 & 59 & 48 & $33 \times 17$ & $25 \times 3$ & $33 \times 16$ \\
\hline G VII & 64 & 55 & 63 & 60 & 54 & 53 & 45 & $21 \times 6$ & $15 \times 4$ \\
\hline G VIII & 63 & 62 & 63 & 59 & 62 & 54 & 54 & $\mathbf{4 9}$ & $27 \times 4$ \\
\hline G IX & 65 & 58 & 57 & 50 & 59 & 54 & 56 & 59 & 5 \\
\hline Média & 67 & 58 & 62 & 59 & 61 & 58 & 58 & 58 & 56 \\
\hline
\end{tabular}

R. Árvore, Viçosa-MG, v.27, n.3, p.357-363, 2003 


\section{CONCLUSÕES}

Constatou-se uma distância genética média entre os genótipos de Eucalyptus de 54\%. Os genótipos 05 e 09; 09 e 10;09 e 19;09 e 25; 09 e 33; 09 e 35; 09 e 36; 09 e $44 ; 10$ e $33 ; 12$ e $19 ; 12$ e 33 ; e 12 e 39 apresentaram distâncias entre si iguais ou superiores a $70 \%$, o que permite a sua seleção para ampliação da base genética em programa de melhoramento .

Através da análise de agrupamento estabelecida pelo dendrograma método UPGMA, usando como critério de corte a $80 \%$ da distância genética total, constatou-se a formação de nove grupos distintos e com alta divergência entre si.

As estimativas de divergência genética entre os grupos encontrados permitiram definir progenitores para geração de híbridos para futuros programas de melhoramento genético de Eucalyptus spp.

\section{REFERÊNCIAS BIBLIOGRÁFICAS}

BORÉM, A. Melhoramento de plantas. Viçosa, MG: Universidade Federal de Viçosa, 1997. 547 p.

CRUZ, C. D. Genes versão 98.2.0: Programa para análise e processamento de dados baseado em modelos de genética e estatística experimental. Viçosa, MG: UFV, 1998. ??páginas??

ESBRISSE, E. J. Associação entre distâncias genéticas, determinadas com marcadores moleculares RAPD e características fenotípicas em Eucalyptus spp. 1998. $51 \mathrm{f}$. Dissertação (Mestrado em Genética e Melhoramento) Universidade Federal de Viçosa, Viçosa, 1998.

FERREIRA, M. E.; GRATTAPAGLIA, D. Introdução ao uso de marcadores RAPD e RFLP em análise genética. 2.ed. Brasília: EMBRAPA/CENARGEN, 1996. 220 p.

GRATTAPAGLIA, D. et al. Molecular genetic mapping of economically important traits in Eucalyptus grandis. In: BIOLOGICAL SCIENCES SYMPOSIUM, 1994, ??Local??. Proceedings... ??Local: Editora??, 1994. ??páginas??
HOSPITAL, F. et al. More on the efficiency of markerassisted selection. Theoretical and Applied Genetics, v. 95, n. 8, p. 1181-1189, 1997.

JACCARD, P. Nouvelles recherches sur la distribution florale. Bulletin de la Societé Vanddoise des Sciences Natureles, v. 44, p. 223-270, 1908.

LANDE, R.; THOMPSON, R. Efficiency of markerassisted selection in the improvement of quantitative traits. Genetics, v. 124, n. 3, p. 743-756, 1990.

MILACH, S. C. K. Principais tipos de marcadores moleculares e suas características. In: MILACH, S. C. K. Marcadores moleculares em plantas. Porto Alegre: UFRGS, 1998. p. 17-28.

MILACH, S. C. K. Marcadores de DNA - aplicações no melhoramento de plantas (on line). Disponível:

millach@vortex.ufrgs.br (capturado em 15 de março de 1999).

MULLIS, K.; FALOONA, F. Specifc synthesis of DNA in vitro via a polymerase catalyzed chain reaction. Methods Enzymology, v. 155, p. 335, 1987.

NIENHUIS, J. et al. Genetic relationships among cultivars and lines of lima bean (Phaseolus lunatus L.) as measured by RAPD markers. Journal of the American Society for Horticultural Science, v. 120, n. 2, p. 300-306, 1995.

SKROCH, P. W.; TIVANG, J.; NIENHUIS, J. Analysis of genetic relationship using RAPD marker data. In: IUFRO INTERNATIONAL CONFERENCE: "Breeding tropical trees" Section 202-08, 1992, Cali, Colombia.

Proceedings... Cali: 1992. p. 26-30.

WHITTAKER, J. et al. Using marker maps in markerassisted selection. Genet. Res. v. 66, p. 255-265, 1995.

WILLIAMS, J. G. K. et al. DNA polymorphisms amplified by arbitrary primers are useful as genetic markers. Nucleic Acids Research, v. 18, n. 22, p. 6531-6535, 1990. 